\title{
Estudio de los procesos de enseñanza-aprendizaje del flamenco a través de entrevistas. La visión de las mujeres
}

\section{Study for the Teaching-Learning Processes of Flamenco through interviews. A woman's view}

\author{
Rosa de las Heras Fernández \\ rosa.heras@unir.ne \\ Departamento de Didáctica de la Música y la Expresión Corporal \\ Universidad Internacional de La Rioja \\ La Rioja, España \\ ORCID: http://orcid.org/0000-0001-5221-1086 \\ Desirée García Gil \\ desirega@ucm.es \\ Departamento de Didáctica de las Lenguas, Artes y Educación Física \\ Universidad Complutense de Madrid \\ Madrid, España \\ ORCID: https://orcid.org/0000-0002-0591-6873
}

doi: 10.7203/LEEME.43.14587

Recibido: 12-12-19 Aceptado: 07-05-19. Contacto y correspondencia: Desirée García-Gil, Departamento de Música. Facultad de Educación Universidad Complutense de Madrid, Ed. La Almudena, Avenida Rector Royo Villanova, s/n, 28040. Madrid. España.

\section{Resumen}

Los estudios reglados de flamenco hicieron su aparición en el currículum oficial a partir de la entrada en vigor de la Ley Orgánica 1/1990, de 3 de octubre de 1990, de Ordenación General del Sistema Educativo. Sin embargo, un buen número de profesionales realizaron sus estudios con antelación a dicha disposición gubernamental, por lo que su enseñanza siguió los mismos cauces. La presente investigación estudia el modo en el que se lleva a cabo el proceso de enseñanza-aprendizaje de la música y el baile flamenco, por medio de mujeres, dentro de contextos formales, no formales e informales. Para ello, se diseña y valida una entrevista estructurada, que es aplicada a un total de 6 docentes. Los resultados, obtenidos a través de la codificación categórica por medio del software ATLAS.ti ponen de manifiesto la falta de conocimiento musical de las entrevistadas, así como la influencia docente en los procesos de aprendizaje coreográficos.

Palabras clave: Entrevistas, Enseñanza, Aprendizaje, Mujeres, flamenco.

\section{Abstract}

Regulated studies of flamenco made their appearance in the official curriculum after the entry into force of the Organic Law 1/1990, of October 3, 1990, on the General Regulation of the Educational System. Nevertheless, a good number of professionals carried out their studies in advance of said governmental disposition, thus explaining why their pedagogy followed the same channels. This research studies the way in which the teaching-learning process of flamenco music and dance is carried out, through women, within formal, informal and casual contexts. For this, we designed and validated a structured interview, which we implemented with a total of 6 teachers. The results, obtained through the categorical coding through the ATLAS.Ti show the lack of musical knowledge of those interviewed and the influence of teaching in the choreographic learning processes.

Key words: Interviews, Teaching, Learning, Women, flamenco.

@ROSA DE LAS HERAS FERNÁNDEZ Y DESIRÉE GARCÍA GIL. THE CONTENT OF THIS ARTICLE IS THE SOLE RESPONSIBILITY OF THE AUTHORS. THE REVISTA ELECTRÓNICA DE LEEME AND UNIVERSITAT DE VALENCIA ARE NOT LABLE FOR ANY LEGAL ACTIONS THAT MAY ARISE INVOLVING THE ARTICLE'S CONTENT. REVISTA ELECTRÓNICA DE LEEME - LISTA ELECTRÓNICA EUROPEA DE MÚSICA EN LA EDUCACIÓN-HTTP://OJS.UV.ES/INDEX/PHP/LEEME/INDEX. ISSN: 1575-9563. EDITORES: UNIVERSIDAD DE VALENCIA Y JESÚS TEJADA GIMÉNEZ. VISIBILIDAD DE ESTA REVISTA: SCOPUS, EMERGING SOURCES CITATION INDEX (CLARIVATE), EBSCO, CINDOC (CSIC), CITEFACTOR, COPAC, DIALNET, DICE (CSIC), DOAJ, E-REVISTAS (CSIC), EBSCO PREMIER, ERIH+, GALE CENGAGE LEARNING, IN-RECS, IRESIE, LATINDEX, MIAR, OCLC WORLDCAT, RESH, REDIB, RILM CORE JOURNALS, SUDOC, ULRICHS, ESTA REVISTA ESTÁ PUBLICADA CON EL APOYO INSTITUCIONAL DE REDIRIS-CONSEJO SUPERIOR DE INVESTIGACIONES CIENTIFICAS Y ES DE ACCESO LIBRE. CREATIVE COMMONS LICENSE 4.0 BY 


\section{Introducción}

A partir del curso académico 1969-1970, la bailarina y catedrática Guillermina Martínez Cabrejas «Mariemma» establece en los programas oficiales del conservatorio de Madrid el baile flamenco como una de las cuatro "ramas" de la Danza Española junto al Bolero, las Danzas Folclóricas y la Danza Estilizada. Dicha "división ha sido aceptada por buena parte del mundo académico y profesional, reconociendo su utilidad en el campo de la enseñanza" (Ley 10/2015, p.121896). De hecho, esta configuración ha permanecido inalterable incluso cuando la Danza Española -junto al resto de especialidades, Danza Clásica y Danza Contemporánea- se estructuró en tres grados (elemental, medio y superior) de manera similar a como se hizo en las enseñanzas de música (Ley Orgánica 1/1990 de 3 de octubre, de Ordenación General del Sistema Educativo -en adelante, LOGSE-, p.28934). En concreto, el baile flamenco se mantuvo como una asignatura dentro de la citada especialidad, en su grado medio, a través del Real Decreto 1254/1997 (p.26309). Posteriormente, además de permanecer en su configuración primigenia como materia de estudios, pasó a ser otra de las "especialidad[es] de las enseñanzas profesionales de Danza", de seis años de duración, en virtud del Real Decreto 85/2007 (p.6250) (Tablas 1 y 2).

Tabla 1. Enseñanzas profesionales de Danza. Especialidad Baile Flamenco

\begin{tabular}{ll}
\hline ASIGNATURA COMÚN & ASIGNATURAS ESPECÍFICAS \\
\hline Música & Técnicas básicas de danza \\
& Danza española \\
& Baile flamenco \\
& Estudio del cante de acompañamiento \\
& Estudio de la guitarra de acompañamiento \\
\hline
\end{tabular}

Fuente: Elaboración propia a partir del $R D$ 85/2007

Tabla 2. Enseñanzas profesionales de Danza. Especialidad Danza Española

\begin{tabular}{ll}
\hline ASIGNATURA COMÚN & ASIGNATURAS ESPECÍFICAS \\
\hline Música & Danza clásica \\
& Escuela bolera \\
& Danza estilizada \\
& Flamenco \\
& Folklore \\
\hline
\end{tabular}

Fuente: Elaboración propia a partir del $R D$ 85/2007 
Tres años después, cuando se publica el Real Decreto 632/2010, en el que se regula el contenido básico de las enseñanzas artísticas superiores de Grado en Danza se vuelve a modificar la estructura y nomenclatura del plan de estudios, dividiéndose de la siguiente manera: se distinguen dos especialidades- Pedagogía de la Danza y Coreografía e Interpretación-, divididas a su vez en diferentes itinerarios -"“[1]as Administraciones educativas, vista la propuesta de los centros, al establecer los correspondientes planes de estudios podrán disponer diversos itinerarios académicos en cada una de las especialidades" (p.48505). Dentro de ellos, se realizan ahora los diferentes estilos de baile. En virtud de esto, serán los conservatorios los que decidan la organización de sus planes de estudios. Así, por ejemplo, en el de la Comunidad de Madrid (Tablas 3, 4 y 5), el baile flamenco aparece como asignatura en la especialidad Coreografía e Interpretación, para los tres itinerarios -Coreografía, Interpretación y Danza y Tecnología- en todos los cursos, con un carácter obligatorio de especialidad y con una carga lectiva diferente.

Tabla 3. Grado en Danza. Especialidad Coreografía e Interpretación (itinerario Coreografía)

\begin{tabular}{|c|c|c|c|c|c|c|}
\hline MATERIA & ASIGNATURA & $\begin{array}{l}\text { CARÁCTER } \\
\text { DE LA } \\
\text { ASIGNATURA }\end{array}$ & $\begin{array}{l}\text { ECTS } \\
1^{\circ} \\
\text { curso } \\
\end{array}$ & $\begin{array}{l}\text { ECTS } \\
2^{\circ} \\
\text { curso } \\
\end{array}$ & $\begin{array}{l}\text { ECTS } \\
3^{\circ} \\
\text { curso } \\
\end{array}$ & $\begin{array}{l}\text { ECTS } \\
4^{\circ} \\
\text { curso } \\
\end{array}$ \\
\hline \multirow{3}{*}{$\begin{array}{l}\text { Historia de la Danza y } \\
\text { Humanidades }\end{array}$} & Historia de la Danza I y II & ${ }^{1} \mathrm{FB}$ & 3 & 3 & & \\
\hline & $\begin{array}{l}\text { Historia del Arte y la Cultura } \\
\text { I y II }\end{array}$ & FB & 3 & 3 & & \\
\hline & $\begin{array}{l}\text { Danza, Arte y Humanidades I } \\
\text { y II }\end{array}$ & FB & & & 3 & 3 \\
\hline \multirow{5}{*}{$\begin{array}{l}\text { Ciencias de la Salud } \\
\text { Aplicada a la Danza }\end{array}$} & Anatomía, Biomecánica y & ${ }^{2} \mathrm{OE}$ & 4 & & & \\
\hline & $\begin{array}{l}\text { Patología aplicadas a la } \\
\text { Danza }\end{array}$ & & & & & \\
\hline & Fisiología y Nutrición & $\mathrm{OE}$ & & 3 & & \\
\hline & Aplicadas a la Danza & & & & & \\
\hline & Técnicas Corporales I y II & $\mathrm{OE}$ & & & 3 & 2 \\
\hline $\begin{array}{l}\text { Técnicas de Danza y } \\
\text { Movimiento }\end{array}$ & $\begin{array}{l}\text { Técnicas de Danza, según } \\
\text { estilos: D. Clásica y D. } \\
\text { Contemporánea/D. Española } \\
\text { y Baile Flamenco, I, II y III }\end{array}$ & $\mathrm{OE}$ & 18 & 18 & 9 & \\
\hline \multirow{5}{*}{$\begin{array}{l}\text { Técnicas de Composición } \\
\text { Coreográfica y de } \\
\text { Improvisación. Sistemas } \\
\text { y Herramientas de } \\
\text { Creación }\end{array}$} & Análisis del Movimiento I y II & $\mathrm{OE}$ & 3 & 2 & & \\
\hline & $\begin{array}{l}\text { Composición e Improvisación } \\
\text { I, II, III y IV }\end{array}$ & $\mathrm{OE}$ & 4 & 3 & 6 & 2 \\
\hline & $\begin{array}{l}\text { Talleres de Creación, según } \\
\text { estilos: D. Clásica, D. }\end{array}$ & $\mathrm{OE}$ & 3 & 4 & 15 & 7 \\
\hline & $\begin{array}{l}\text { Contemporánea / D. Española } \\
\text { y Baile Flamenco I,II,III y IV }\end{array}$ & & & & & \\
\hline & $\begin{array}{l}\text { Análisis y Práctica del } \\
\text { Repertorio, según estilos: D. }\end{array}$ & $\mathrm{OE}$ & 4 & 6 & 6 & 2 \\
\hline
\end{tabular}

\footnotetext{
${ }^{1}$ Formación básica.

${ }^{2}$ Obligatoria de especialidad.
} 


\begin{tabular}{|c|c|c|c|c|c|c|}
\hline $\begin{array}{l}\text { Análisis y Práctica de las } \\
\text { Obras Coreográficas y } \\
\text { del Repertorio }\end{array}$ & $\begin{array}{l}\text { Clásica, D. Contemporánea, } \\
\text { D. Española y Baile } \\
\text { Flamenco, I, II, III y IV } \\
\text { Taller de Interpretación, } \\
\text { según estilos: D. Clásica y D. } \\
\text { Contemporánea y D. } \\
\text { Española y Baile Flamenco I } \\
\text { y II }\end{array}$ & $\mathrm{OE}$ & 12 & 12 & & \\
\hline $\begin{array}{l}\text { Música y Lenguajes } \\
\text { Sonoros Aplicados a la } \\
\text { Danza }\end{array}$ & $\begin{array}{l}\text { Música Aplicada a la Danza I, } \\
\text { II y III }\end{array}$ & $\mathrm{OE}$ & 3 & 3 & 3 & \\
\hline Escenificación y & Espacio Escénico & $\mathrm{OE}$ & & & 2 & \\
\hline Dramaturgia & $\begin{array}{l}\text { Dramaturgia } \\
\text { Técnicas del Espectáculo }\end{array}$ & $\begin{array}{l}\mathrm{OE} \\
\mathrm{OE}\end{array}$ & & & 3 & 6 \\
\hline $\begin{array}{l}\text { Tecnologías Aplicadas a } \\
\text { la Danza }\end{array}$ & Danza y Tecnología I & $\mathrm{OE}$ & & & 3 & 3 \\
\hline $\begin{array}{l}\text { Organización, Gestión y } \\
\text { Elaboración de Proyectos } \\
\text { Artísticos }\end{array}$ & $\begin{array}{l}\text { Organización, Gestión y } \\
\text { Elaboración de Proyectos } \\
\text { Artísticos }\end{array}$ & $\mathrm{OE}$ & & & 4 & 3 \\
\hline & $\begin{array}{l}\text { Introducción a la Metodología } \\
\text { de la Investigación Artística }\end{array}$ & $\mathrm{OE}$ & & & & 2 \\
\hline & $\begin{array}{l}\text { Psicología de los Grupos y de } \\
\text { las Organizaciones }\end{array}$ & $\mathrm{OE}$ & & & & 2 \\
\hline & Optativas & & 3 & 3 & 3 & 6 \\
\hline Prácticas & & & & & & 14 \\
\hline Fin de grado & & & & & & 8 \\
\hline ECTS TOTALES & & & & 60 & 60 & 60 \\
\hline
\end{tabular}

Fuente: Elaboración propia a partir del $R D$ 632/2010

@ROSA DE LAS HERAS FERNÁNDEZ Y DESIRÉE GARCIA GIL. THE CONTENT OF THIS ARTICLE IS THE SOLE RESPONSIBILITY OF THE AUTHORS. THE REVISTA ELECTRÓNICA DE LEEME ELECTRÓNICA EUROPEA DE MÚSICA EN LA EDUCACIÓN-HTTP://OJS.UV.ES/INDEX/PHP/LEEME/INDEX. ISSN: 1575-9563. EDITORES: UNIVERSIDAD DE VALENCIA Y JESÚS TEJADA GIMÉNEZ. VISIBILIDAD DE ESTA REVISTA: SCOPUS, EMERGING SOURCES CITATION INDEX (CLARIVATE), EBSCO, CINDOC (CSIC), CITEFACTOR, COPAC, DIALNET, DICE (CSIC), DOAJ, E-REVISTAS (CSIC), EBSCO PREMIER, ERIH+, GALE CENGAGE LEARNING, IN-RECS, IRESIE, LATINDEX, MIAR, OCLC WORLDCAT, RESH, REDIB, RILM CORE JOURNALS, SUDOC, ULRICHS, ESTA REVISTA ESTÁ PUBLICADA CON EL APOYO INSTITUCIONAL DE REDIRIS-CONSEJO SUPERIOR DE INVESTIGACIONES CIENTIFICAS Y ES DE ACCESO LIBRE. CREATIVE COMMONS LICENSE 4.0 BY 
Tabla 4. Grado en Danza, especialidad Coreografía e Interpretación (itinerario Interpretación)

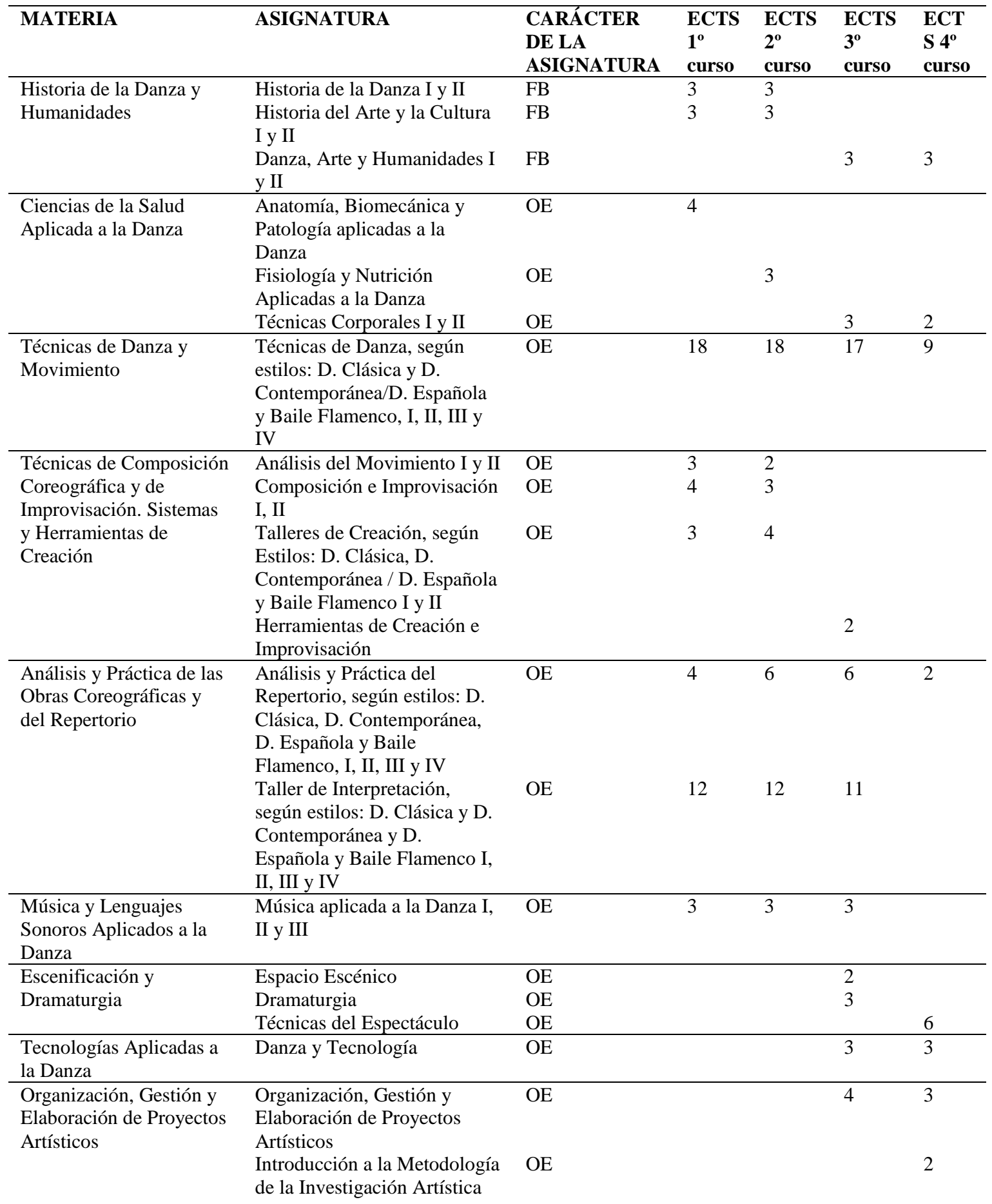

@ROSA DE LAS HERAS FERNÁNDEZ Y DESIRÉE GARCÍA GIL. THE CONTENT OF THIS ARTICLE IS THE SOLE RESPONSIBILITY OF THE AUTHORS. THE REVISTA ELECTRÓNICA DE LEEME AND UNIVERSITAT DE VALĖNCIA ARE NOT LIABLE FOR ANY LEGAL ACTIONS THAT MAY ARISE INVOLVING THE ARTICLE'S CONTENT. REVISTA ELECTRÓNICA DE LEEME -LISTA ELECTRÓNICA EUROPEA DE MÚSICA EN LA EDUCACIÓN-HTTP://OJS.UV.ES/INDEX/PHP/LEEME/INDEX. ISSN: 1575-9563. EDITORES: UNIVERSIDAD DE VALENCIA Y JESÚS TEJADA GIMÉNEZ. VISIBILIDAD DE ESTA REVISTA: SCOPUS, EMERGING SOURCES CITATION INDEX (CLARIVATE), EBSCO, CINDOC (CSIC), CITEFACTOR, COPAC, DIALNET, DICE SUDOC, ULRICHS, ESTA REVISTA ESTÁ PUBLICADA CON EL APOYO INSTITUCIONAL DE REDIRIS-CONSEJO SUPERIOR DE INVESTIGACIONES CIENTIFICAS Y ES DE ACCESO LIBRE. CREATIVE COMMONS LICENSE $4.0 \mathrm{BY}$ 
revista electrónica

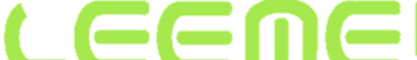

Electronic Journal of Music in Education

Revista arbitrada de investigación y y plicaciones en Educación Musical
Peer reviewed juurnal of research and applications in Music Education ISSN: $1575-9563$
ROSA DE LAS HERAS FERNÁNDEZ Y DESIRÉE GARCIA GIL
ESTUDIO DE LOS PROCESOS DE ENSENAANA-APRENDIZAJE DEL FLAMENCO A TRAVÉSS DE

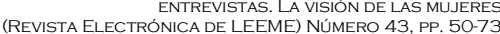
HTTPS://OJS.UV.ES/INDEX.PHP/LEEME/INDEX

Psicología de los Grupos y de

OE 2 las Organizaciones

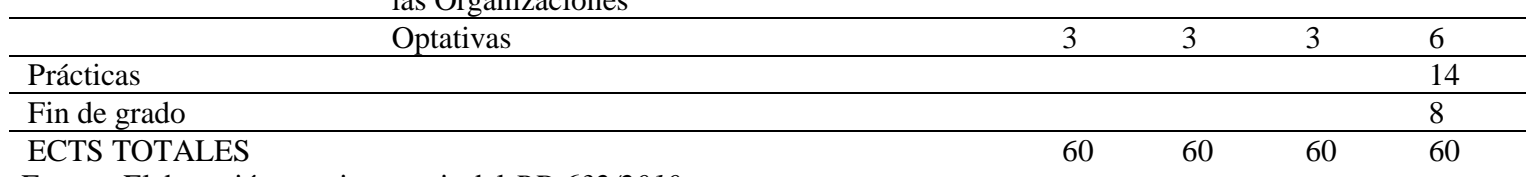

Fuente: Elaboración propia a partir del $R D$ 632/2010

@ROSA DE LAS HERAS FERNÁNDEZ Y DESIRÉE GARCIAA GIL. THE CONTENT OF THIS ARTICLE IS THE SOLE RESPONSIBILITY OF THE AUTHORS. THE REVISTA ELECTRÓNICA DE LEEME AND UNIVERSITAT DE VALĖNCIA ARE NOT LIABLE FOR ANY LEGAL ACTIONS THAT MAY ARISE INVOLVING THE ARTICLE'S CONTENT. REVISTA ELECTRONICA DE LEEME - USTA ELECTRÓNICA EUROPEA DE MÚSICA EN LA EDUCACIÓN-HTTP://OJS.UV.ES/INDEX/PHP/LEEME/INDEX. ISSN: 1575-9563. EDITORES: UNIVERSIDAD DE VALENCIA Y JESÚS TEJADA GIMÉNEZ. VISIBILIDAD DE ESTA REVISTA: SCOPUS, EMERGING SOURCES CITATION INDEX (CLARIVATE), EBSCO, CINDOC (CSIC), CITEFACTOR, COPAC, DIALNET, DICE (CSIC), DOAJ, E-REVISTAS (CSIC), EBSCO PREMIER, ERIH+, GALE CENGAGE LEARNING, IN-RECS, IRESIE, LATINDEX, MIAR, OCLC WORLDCAT, RESH, REDIB, RILM CORE JOURNALS, SUDOC, ULRICHS, ESTA REVISTA ESTÁ PUBLICADA CON EL APOYO INSTITUCIONAL DE REDIRIS-CONSEJO SUPERIOR DE INVESTIGACIONES CIENTIFICAS Y ES DE ACCESO LIBRE. CREATIVE COMMONS LICENSE 4.0 BY 
Electronic Journal of Music in Education

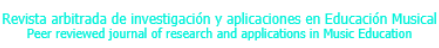

ISSN: 1575-9563

Tabla 5. Grado en Danza. Especialidad Coreografía e Interpretación (itinerario Danza y Tecnología)

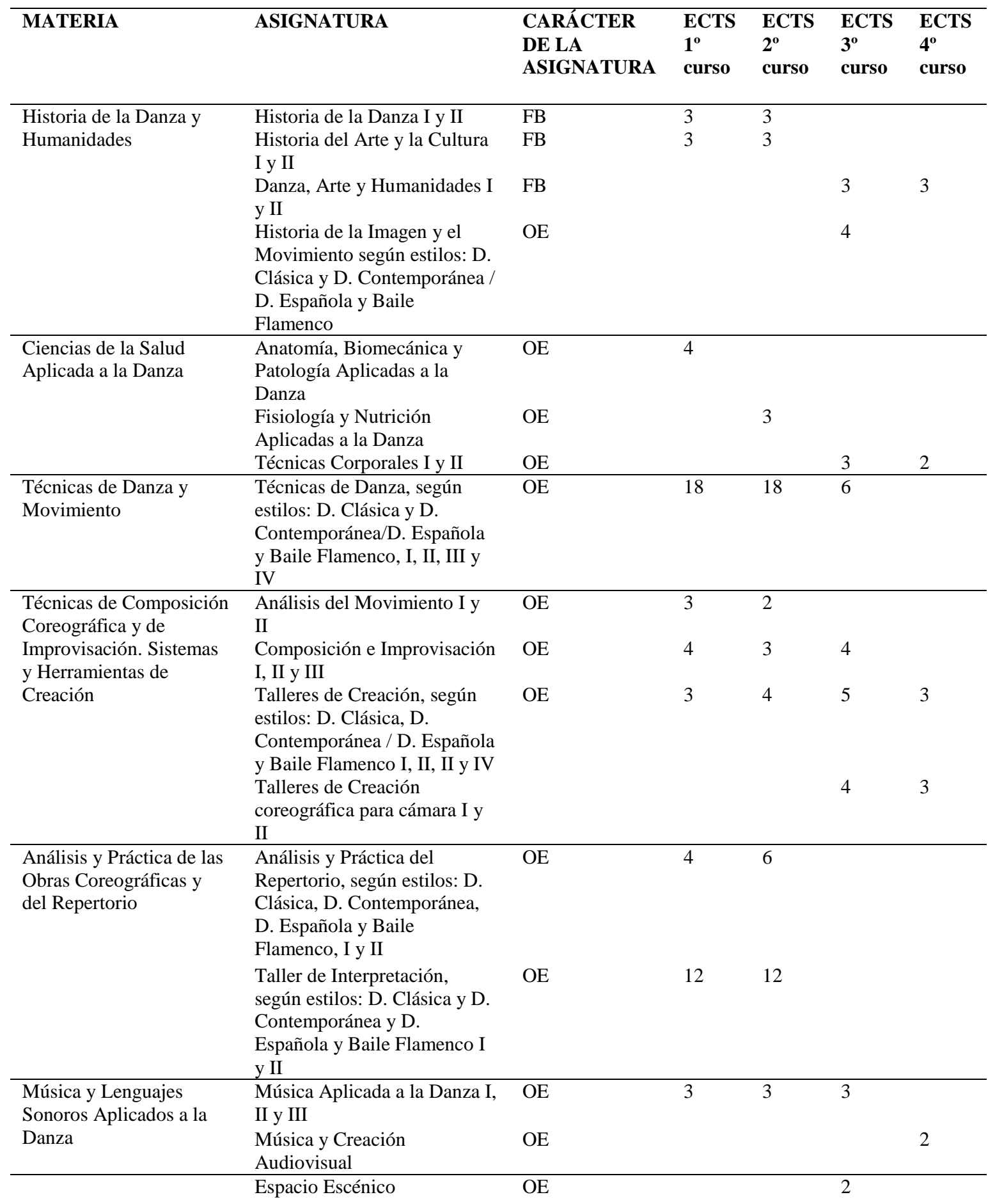

@ROSA DE LAS HERAS FERNÁNDEZ Y DESIRÉE GARCIAA GIL. THE CONTENT OF THIS ARTICLE IS THE SOLE RESPONSIBILITY OF THE AUTHORS. THE REVISTA ELECTRÓNICA DE LEEME AND UNIVERSITAT DE VALĖNCIA ARE NOT LIABLE FOR ANY LEGAL ACTIONS THAT MAY ARISE INVOLVING THE ARTICLE'S CONTENT. REVISTA ELECTRÓNICA DE LEEME -LISTA ELECTRÓNICA EUROPEA DE MÚSICA EN LA EDUCACIÓN-HTTP://OJS.UV.ES/INDEX/PHP/LEEME/INDEX. ISSN: 1575-9563. EDITORES: UNIVERSIDAD DE VALENCIA Y JESÚS TEJADA GIMÉNEZ. VISIBILIDAD DE ESTA REVISTA: SCOPUS, EMERGING SOURCES CITATION INDEX (CLARIVATE), EBSCO, CINDOC (CSIC), CITEFACTOR, COPAC, DIALNET, DICE (CSIC), DOAJ, E-REVISTAS (CSIC), EBSCO PREMIER, ERIH+, GALE CENGAGE LEARNING, IN-RECS, IRESIE, LATINDEX, MIAR, OCLC WORLDCAT, RESH, REDIB, RILM CORE JOURNALS, SUDOC, ULRICHS, ESTA REVISTA ESTÁ PUBLICADA CON EL APOYO INSTITUCIONAL DE REDIRIS-CONSEJO SUPERIOR DE INVESTIGACIONES CIENTIFICAS Y ES DE ACCESO LIBRE. CREATIVE COMMONS LICENSE 4.0 BY 


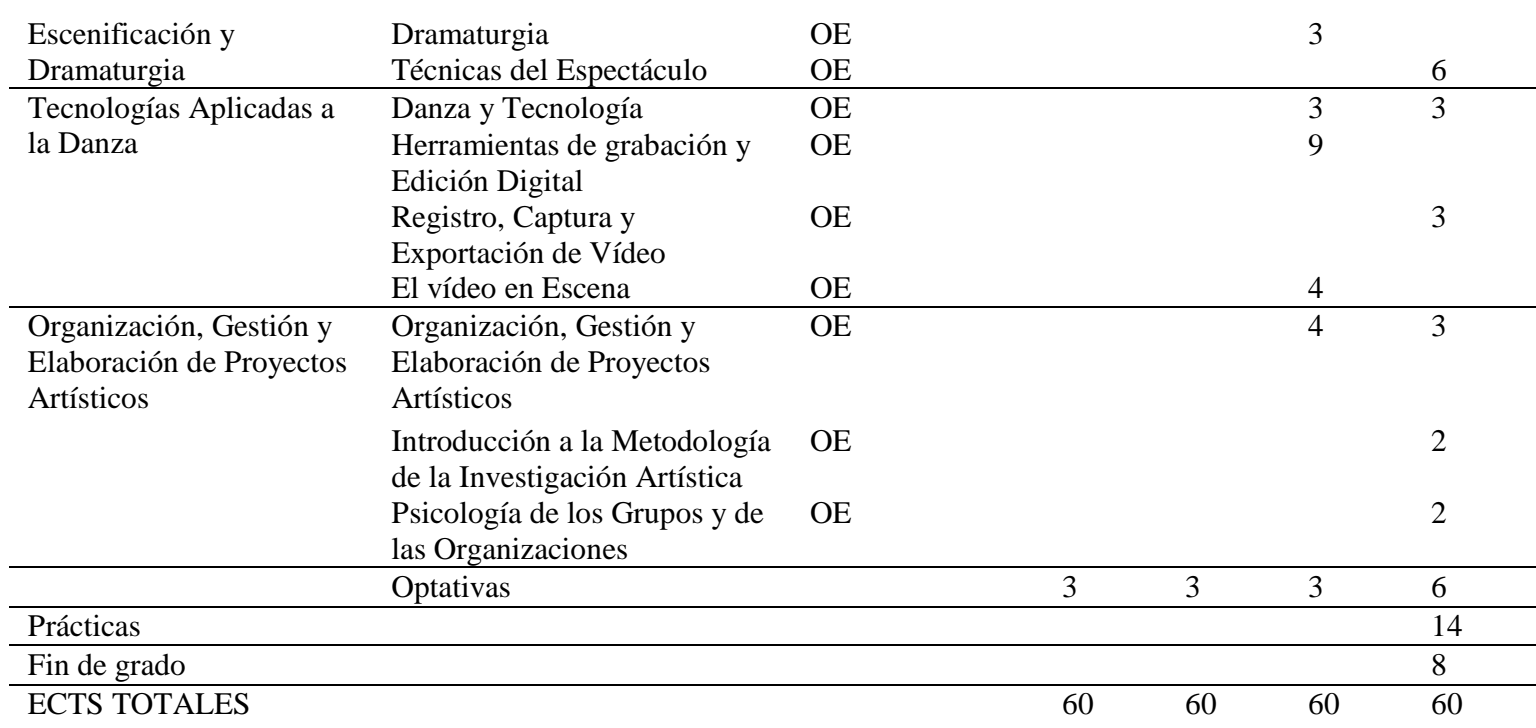

Fuente: Elaboración propia a partir del RD 632/2010

\subsection{Enseñanza-aprendizaje del flamenco. Algunas cuestiones básicas}

De forma concreta, en el flamenco se ha utilizado principalmente el estilo de enseñanza «Comando» (Mostton, 1981), empleado en Educación Física en la que el profesor hace y el alumno repite. Este estilo ha sido predominante en este tipo de enseñanza, pues como señalan Syrmpas y Digelidis (2014) se tiende a enseñar tal y como se aprende. En esta línea, Casas-Mas, Pozo y Montero (2014) llevaron a cabo un estudio para determinar cómo se producía el proceso de aprendizaje-enseñanza musical fuera de contextos formales en los estilos flamenco, jazz y clásico. Los investigadores concluyeron que la cultura flamenca difiere significativamente de las restantes en cuanto a concepción de la enseñanza, estando más cercana a la construcción directa de aprendizaje que a la corriente constructivista del mismo. De tal modo, la investigación reflejó que los estudiantes de flamenco optan por un formato de enseñanza-aprendizaje regulado externamente y basado en la copia: el maestro es quien decide el programa de obras y muestra a los alumnos cómo interpretarlas hasta que, con la práctica, son capaces de emularle. Así, los alumnados son significativamente menos propensos a elegir su propio repertorio, al tiempo que su forma de estudio consiste en la memorización de fragmentos y su continua repetición hasta que son capaces de interpretar la pieza al completo. La opinión del maestro sirve entonces para corregir al estudiantado, haciéndoles notar lo que está mal, diciéndoles cómo resolverlo, sin que estos cuestionen ni el criterio ni el procedimiento ya metodológico ya musical del profesor. En definitiva, se trata de una cultura centrada en la transmisión oral en la que se prioriza la reproducción de modelos eficientes para garantizar su preservación. 
Por su parte, Cruces (2004) señala los distintos contextos en los que el flamenco se ha ido desarrollando: lo muestra a través de binomios simplificadores en espacios privados «de uso» y espacios públicos como «flamenco de cambio». En los espacios de uso señala: lugares de sociabilidad informal, fiestas no intencionales, fiestas intencionales (bodas, bautizos, comuniones, etc.), acontecimientos sociales festivos, ámbitos laborales y vida cotidiana. En cuanto a los espacios públicos indica: academias y salones de baile, cafés cantantes, teatros, plazas de toros, festivales, peñas, y fiestas pagadas. Todos estos han sido contextos de aprendizaje, formales, no formales e informales, en los que el baile flamenco se ha transmitido.

\subsection{Mujeres y flamenco}

Históricamente, las mujeres han tenido una marcada presencia en las representaciones de baile. Ya en el siglo XVIII, las fuentes documentales -como por ejemplo, «Libro de la gitanería de Triana de los años 1740 a 1750 que escribió el Bachiller Revoltoso para que no se imprimiera»- ofrecen testimonio de gitanas que se ganaban la vida ensañando bailes a otras e interpretándolos, es decir, a través de la imitación en contextos informales (se las conocía como "autoras de danza"). Muchas de ellas, como por ejemplo la conocida como «nieta de Balthasar Montes», eran requeridas en las fiestas de la alta aristocracia, atraída por esa forma de baile (Navarro y Pablo, 2005, p.15).

Con todo, la mayoría de fuentes historiográficas, antropológicas y educativas coinciden en señalar que la presencia más importante de la mujer en el baile flamenco se apreciaba en estos tres contextos físicos y dancísticos (Del Campo y Cáceres, 2013; Pohren, 1970; Puig Claramunt, 1977):

- Bailes de candil: el zapateado se consideraba un "baile vivo y gracioso realizado fundamentalmente por mujeres donde se alternaban pasitos menudos de escuela con el típico taconeo" (Atienza, 2015, p. 145).

- Café Cantantes: donde el baile más popular era el tango flamenco -"baile muy pintoresco donde se utilizaba el mantón y el sombrero-, destacaron intérpretes como Rafaela «La Tanguera» y Concha «La Carbonera»" (Atencia, 2015, p.145). Estos se convirtieron en verdaderas escuelas para el aprendizaje del baile flamenco, de las que salieron bailarinas de renombre como Trinidad Huertas «La Cuenca»-formadora de Salud Rodríguez-, Magdalena Seda Loreto, «La Malena»; Rosario Monje, «La Mejorana» (madre de Pastora Imperio), entre otras (Ríos Ruíz, 2002).

- Compañías de Baile: entre las que destaca la de Carmen Amaya, quien fue la primera profesional que crea una compañía formada exclusivamente por personas de etnia 
gitana. Junto a ella, las hermanas Argentinita y Pilar López encabezaron importantes compañías de danza.

Con respectos a esto, debe tenerse en cuenta que el proceso de enseñanza-aprendizaje por y para mujeres, tradicionalmente y hasta su incorporación en el currículum oficial (ver introducción), se llevaba a cabo dentro de dos contextos informales principales: compañías y equipos de baile dedicados a dar espectáculos. Bailaoras como «Lolilla la flamenca», la «Malaguellita», «Maria la Bella», «La Macarrona», Maria del Rosario «La Pantoja», Juana y Fernanda Antúnez, entre otras, fueron mujeres dedicadas a la enseñanza del flamenco a través de las escuelas de bailes surgidas alrededor de las compañías de danza en las que trabajaban (Pantoja Antúnez, 1963).

Así, el magisterio de la mujer en la danza supuso extraer esta especialidad del mundo artístico y llevarlo al espacio académico. Además de las ya mencionadas, se pueden citar otros ejemplos. «Mariemma» recordaba como el magisterio de Antonia Mercé [y Luque, «La Argentinita»] fue decisivo tanto para ella como para sus compañeras de generación: “[...] era ya nuestro gran futuro, la realidad, la revelación de un arte nuevo de bailar la danza española. [...]" (Marinero, 2000, pp.174-175). La futura catedrática del conservatorio de Madrid se ocupó también de su formación en cuanto al conocimiento de los bailes populares desde un punto de vista etnográfico, puesto que "[recorrió] [...] varias regiones españolas, estudiando los bailes regionales más populares, investigando sobre los más olvidados y volviendo a recrearlos" (p.174).

La presente investigación estudia el modo en el que, en la actualidad, la mujer lleva a cabo el proceso de enseñanza-aprendizaje tanto de la música y como del baile flamenco.

\section{Objetivos y método}

A partir de lo expuesto, la presente investigación pretende:

1. Discriminar los contextos educativos en los que se produce el proceso de enseñanzaaprendizaje de la música y el baile flamenco.

2. Verificar la metodología empleada en la enseñanza del flamenco musical y dancístico.

Para llevar a término las finalidades propuestas, se tomó en consideración el paradigma de investigación cualitativa (Gibbs, 2012) y, dentro de este, se optó por la metodología narrativa como modelo de estudio (García-Huidobro, 2016). De tal modo, como instrumento de recogida 
de datos, se implementó un guión de entrevista semi-estructurada (Ruiz-Olabuénaga, 2007) para profesionales de la enseñanza del flamenco, analizando posteriormente los datos obtenidos a través del software informático ATLAS.ti y obteniendo categorías y subcategorías de acuerdo a los preceptos de la Teoría Fundamentada (Birks y Mills, 2011). Por su parte, la triangulación de los datos se consiguió a través del continuo diálogo de la narración obtenida con los resultados de la literatura científica pertinente, a través del proceso de "autenticidad educativa" (Sandín, 2000, p.230).

\subsection{Procedimiento y participantes}

Para llevar a cabo el presente estudio, las investigadoras se pusieron en contacto, mediante correo electrónico con todos los conservatorios superiores y profesionales de la Comunidad de Madrid que tuvieran en su planificación docente estudios de flamenco. Así, se les informó tanto de los objetivos de investigación, como de la necesidad de entrevistar a las mujeres miembros del equipo docente sobre sus percepciones en cuanto a la enseñanza impartida y recibida. En consecuencia, se les dio un plazo de 10 días para que contestarán afirmativa o negativamente a la petición y solicitaran, si así lo estimaban, las preguntas a realizar. A su vez, se siguió el mismo protocolo para las Escuelas de Música y Danza, públicas y privadas, en la enseñanza de este estilo musical. Además de ello, se pudo tener acceso a intérpretes de reconocido prestigio dentro del estilo flamenco: cinco bailaoras y una cantaora. Este criterio se ajusta a lo mencionado por Gibbs (2012) en relación a la investigación cualitativa, donde no es necesaria una gran muestra, sino que ese análisis permita describir, explicar y generar un conocimiento. Se trata por tanto de un enfoque nomotético, que procura exponer lo que las personas, circunstancias y entornos tienen en común para poder explicarlo en función de rasgos comunes. Así, de forma específica, la muestra estuvo conformada por:

(a) Cinco bailaoras cuya formación se llevó a cabo en conservatorios Profesionales de Danza y escuelas privadas. En cuanto a la docencia impartida, dos de ellas ejercieron en el conservatorio Superior de Danza de Madrid en un periodo de contratación trimestral durante el curso académico 2009-10 y 2015-16, y la otra en el conservatorio Profesional de la Comunidad de Madrid desde el curso 2008-09 estando actualmente en activo. Junto a ellas, la tercera y la cuarta profesional de danza fueron profesoras en el mismo curso escolar en escuelas privadas o como docentes de clases extraescolares en el colegio público del mismo contexto geográfico.

(b) Una cantaora. Su formación se llevó a cabo sobre todo con instrucción directa de su propia madre y visionado de interpretaciones vocales de Manolo Caracol, Rafael Farina 
y Camarón de la Isla, principalmente. Impartió docencia a través de clases particulares principalmente.

\subsection{Instrumento}

La recogida de datos se efectuó a través del diseño de un guión de entrevista semiestructurada, construida a partir de categorías obtenidas en la revisión bibliográfica previa y que serviría para llevar a término los objetivos de investigación propuestos:

1. Categoría 1. Datos personales (Kvale, 2011). A partir de ella, se pretendió conocer aspectos relativos a los datos sociales, profesionales y académicos de los entrevistados.

2. Categoría 2. Aprendizaje (Cruces, 2004). Las preguntas aquí formuladas sirvieron para conocer a) los lugares donde se llevó a cabo la formación de las entrevistadas (Fernández, Sagardia, Loroño, de Gauna y Ramos, 2012) y b) los conocimientos adquiridos a través de profesores, maestros y profesionales expertos (Arranz, 2012).

3. Categoría 3. Enseñanza (Syrmpas y Digelidis, 2014). Las cuestiones en este apartado giraron en torno a los saberes conceptuales, procedimentales y actitudinales, así como a la metodología y a los recursos didácticos empleados. Se pretendía conocer si la forma en la que ellos enseñaban mantenía relación directa con la manera en la que habían aprendido.

En cuanto al proceso de validez del instrumento, se llevó a cabo a través de juicio de expertos (Dorantes-Nova, Hernández-Mosquera y Tobón-Tobón, 2016). Los especialistas consultados llevaron a cabo consideraciones sobre la redacción textual de las preguntasinfiriendo en el hecho de que fueran todas abiertas y ajustándose a un lenguaje técnico-sin señalar la eliminación o la inclusión de cuestiones específicas.

\section{Análisis de datos}

El análisis de la información consiguió la discriminación de las categorías y subcategorías presentes en el Gráfico 1 (ver Figura 1), establecidas a partir de la utilización de ATLAS.ti. Este programa permitió tras las transcripciones de las entrevistas, realizar una visión global de los documentos, para poder realizar funciones básicas tales como: codificación simple y codificación múltiple de fragmentos (segmentos a los que se les puede asignar más de un código), además de mapas conceptuales para la construcción de la teoría (Colás y Rebollo, 1993).

\footnotetext{
@ROSA DE LAS HERAS FERNÁNDEZ Y DESIRÉE GARCÍA GIL. THE CONTENT OF THIS ARTICLE IS THE SOLE RESPONSIBILITY OF THE AUTHORS. THE REVISTA ELECTRÓNICA DE LEEME AND UNIVERSITAT DE VALĖNCIA ARE NOT LIABLE FOR ANY LEGAL ACTIONS THAT MAY ARISE INVOLVING THE ARTICLE'S CONTENT. REVISTA ELECTRÓNICA DE LEEME -LISTA ELECTRÓNICA EUROPEA DE MÚSICA EN LA EDUCACIÓN-HTTP://OJS.UV.ES/INDEX/PHP/LEEME/INDEX. ISSN: 1575-9563. EDITORES: UNIVERSIDAD DE VALENCIA Y JESÚS TEJADA GIMÉNEZ. VISIBILIDAD DE ESTA REVISTA: SCOPUS, EMERGING SOURCES CITATION INDEX (CLARIVATE), EBSCO, CINDOC (CSIC), CITEFACTOR, COPAC, DIALNET, DICE SUDOC, ULRICHS, ESTA REVISTA ESTA PUBLICADA CON EL APOYO INSTITUCIONAL DE REDIRIS-CONSEJO SUPERIOR DE INVESTIGACIONES CIENTIFICAS Y ES DE ACCESO LIBRE. CREATIVE COMMONS LICENSE 4.0 BY
} 

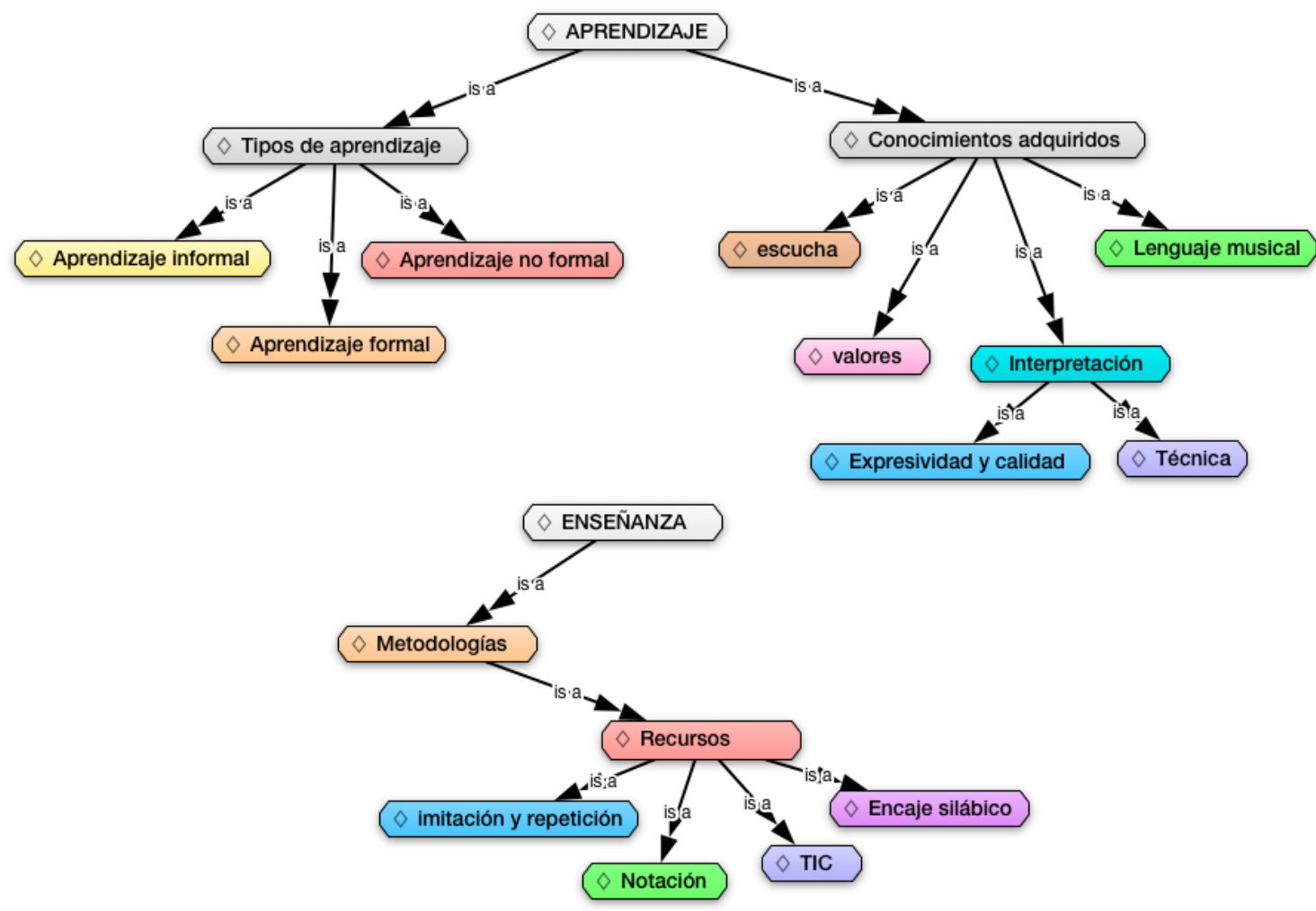

Figura 1. Árbol de categorías ATLAS.ti

Así, de forma concreta y cronológica, inicialmente se realizó un recuento de palabras a través de la herramienta wordcruncher para extraer los términos más frecuentes y relevantes en base a los objetivos de investigación planteados. A partir de ellos, se extrajeron de las entrevistas los códigos y familias de códigos seleccionando, posteriormente, las citas objeto de análisis. Así mismo, se empleó otra estrategia de codificación a través de códigos extraídos del marco teórico, lo que facilitó la discusión de resultados. Posteriormente, a través de la herramienta network se creó la red de vinculación de códigos y familias de códigos, generándose un mapa conceptual.

\subsection{Categoría 1-Aprendizaje}

Las entrevistadas respondieron sobre los tipos de aprendizaje mediante los cuales se instruyeron en el flamenco haciendo alusión a los diferentes contextos formales ("me formé en el conservatorio de Danza Mariemma de Madrid"- Informante 2), no formales ("estuve muchos 
años estudiando en el centro de danza Amor de Dios con varios maestros"- Informante 5) e informales ("lo que más me ha aportado en el aprendizaje del flamenco ha sido trabajar en los tablaos"- Informante 1) donde se llevaron a cabo. Además, las investigadoras tuvieron en cuenta los conocimientos adquiridos a través de las diferentes especialidades de Música (Cante) y Danza (especialmente, Danza Española y Flamenco). Así, por ejemplo, las técnicas de interpretación, vocal o dancística, fueron estudiadas en todos los contextos de aprendizaje, sin embargo, las informantes bailaoras, debido a que se acogen a estudios anteriores a la LOGSE, no recibieron formación musical formal, aunque todas ellas, bailaoras y cantaora, adquirieron conocimientos sobre música flamenca implícitos en su práctica artística. Las técnicas de interpretación aprendidas fueron diversas en las bailaoras: cuerpo, brazos, pies, y la coordinación de los distintos elementos corporales son algunos de los aspectos señalados.

\subsubsection{Sub-categoría 1.1- Contextos de aprendizaje}

Algunas bailaoras recibieron un aprendizaje formal del flamenco en estudios anteriores a la LOGSE. Las informantes recibieron las acreditaciones de finalización de estudios mediante certificaciones expedidas por escuelas de Arte Dramático y Danza o por conservatorios de Danza. Con el Real Decreto 169/2004, se equiparan los estudios completos de danza cursados por las informantes, anteriores a la LOGSE a los estudios superiores de danza establecidos en ella, siempre y cuando, se reunieran una serie de requisitos, o en su defecto, se regularía por medio de los complementos de formación que se establecieron en al artículo 42.3 de la LOGSE.

Por lo que respecta al aprendizaje no formal, las especialistas señalaron que habían recibido clases particulares de profesionales expertos en la materia en academias privadas de la Comunidad de Madrid: así, algunos maestros alquilaban salas especiales para impartir su docencia. Entre ellos, las bailaoras destacaron el nombre del «maestro Ciro», quien tuvo una gran repercusión en varias generaciones de estudiantes.

Por su parte, el aprendizaje informal se produjo compartiendo conocimientos entre compañeros de profesión mediante la experiencia laboral, donde la práctica artística en tablaos y escenarios permite desarrollar habilidades y recursos motores, especialmente en lo que respecta a la improvisación de movimientos (Pablo y Navarro, 2007). Cabe tener en cuenta que en la interpretación de cada uno de los estilos flamencos existe un necesario e importante espacio para la improvisación (Gamboa y Núñez, 2007) y la forma principal de incrementar dichas destrezas es con la actividad escénica. Así, el aprendizaje que adquirieron gracias al trabajo en los tablaos, con la música en directo, fue uno de los más valorados, junto con la satisfacción y el conocimiento procurado al trabajar en compañías de danza profesionales: "La compañía de Joaquín Cortés [...] yo creo que en el tablao he aprendido muchísimo" [informante 4]. Estos 
contextos de aprendizaje que se llevan a cabo en el ámbito laboral se enmarcan dentro de los espacios públicos como una forma de "flamenco de cambio" entendido como nuevos espacios donde se representa el baile flamenco: academias y salones de baile, cafés cantantes, teatros y tablaos (Cruces, 2004).

Dentro de la explicitación de todos estos contextos, se señala otro de los ambientes de aprendizaje informal del flamenco, esto es, en espacios privados. Es lo que Cruces (2004) denomina "flamenco de uso", distintos espacios donde se expone el flamenco, entre ellos, lugares de vecindad, como los patios de vecinos y vida cotidiana, como cantar como costumbre personal. Así lo exponía la cantaora entrevistada: "mi principal maestra ha sido mi madre. Mi madre que ha sido cantaora y bueno yo empecé cantando por ella y siempre me fijaba cuando cantaba" [Informante 6]. Otra forma de aprendizaje informal que manifiesta la cantaora fue de forma autodidacta a través de la audición y visualización de grabaciones de intérpretes expertos en la materia ("como Caracol, Farina, gente así más moderna como Camarón, pero sobre todo los antiguos", [Informante 6]).

\subsubsection{Subcategoría 1.2- Conocimientos adquiridos}

Puesto que las informantes no realizaron los estudios regulados por el Real Decreto 1254/1997, no recibieron formación musical académica en las enseñanzas formales, por tanto, manifestaban tener conocimientos sobre danza y no así puramente musicales implícitos en la práctica de la danza, como es la rítmica del zapateado: “icónchale! Mira, sería buena idea que las alumnas supieran escribir música para saber muy bien dónde van los pasos” [Informante 3].

Entre los conocimientos adquiridos, las informantes mostraron disparidad en cuanto a la naturaleza de los mismos. Así, algunas señalaron que el aprendizaje del flamenco les había procurado (a) valores artísticos ("expresar realmente el flamenco puro" [Informante 3]), (b) instrucción didáctica ("era una persona que te sabía decir las cosas de manera muy clara y concisa, pero sin tenerte que ofender" [informante 4]), y (c) escucha receptiva ("escuchar tranquilamente un buen cante" [informante 6]), entre otros. Como contenido fundamental de aprendizaje, las bailaoras destacaron:

(a) La técnica conseguida en los gestos corporales: "Entonces tenía la clase de pies, la clase de palillos, la clase de vueltas, o sea, todo iba por partes [Informante 5],

(b) La expresión, estética y manera de realizar los movimientos según el carácter de cada estilo flamenco, lo que alguna denominó "la forma de baile" [Informante 1]. 
En cuanto a las técnicas corporales, las bailaoras destacaron aspectos musicales implícitos en la ejecución del baile, como son los diferentes ritmos interpretados en el zapateado ("de la China, los tiempos, los contratiempos, los "sincopaos"”, [Informante 3]). Sin embargo, debido a la falta de conocimiento musical que mostraron sus propios maestros, estos conceptos no fueron impartidos de forma correcta. Los profesores en la enseñanza del flamenco no explican conceptos, sino que enseñan a zapatear aprendiendo un ritmo "de oído" y luego, a veces, adjudican un ritmo a un concepto musical de manera incorrecta pues además lo desconocen (De las Heras-Fernández, 2017).

En lo referente a la forma de baile, se alude a una manera peculiar de realizar los gestos y los movimientos estéticos característicos en los intérpretes del flamenco. A veces, este modelo de expresión corporal se califica como "puro", entendido este término a raíz de la idea de que el flamenco "es cosa de sangre, opinión tan equivocada como tenaz, error del siglo XX, asunto embarazoso, [y esto se debe a que] Antonio Mairena inventó una tradición según sus intereses en el flamenco" (Steingress, 2004, p.192). La defensa de esta teoría no refleja una protección a un valor artístico, "sino que dicha preocupación camufla la instrumentalización del flamenco para otros fines, fines nacionalistas o regionalistas e incluso provincialistas" (p.188). En este mismo sentido, y haciendo énfasis en la afirmación de que el flamenco «se aprende», Martínez (1969) pone de manifiesto que "al maestro, le basta un conocimiento profundo de esta técnica para poder enseñar eficientemente, sin que sea necesario haber nacido gitano o andaluz" (p.83). Por su parte, Cruces (2004) señala las características asociadas al término de pureza en flamenco, en contraposición a la impureza/contaminación. Así, en cuanto al primer vocablo "pureza", el especialista lo atribuye a la etnia gitana, mientras que el segundo, a la etnia no gitana.

Esta forma de pensar encuentra un paralelismo claro con la forma de pensar de las entrevistadas: "de Tati, ella me ha enseñado a expresar realmente el flamenco puro " [Informante 3], subrayando un flamenco menos académico, más artístico, más espontáneo y más racial (Ríos, 2002). Así mismo, la forma en el baile también se ha asociado a un conjunto de movimientos que se coreografían, diferenciándolos de un baile improvisado, o lo que es lo mismo, el baile basado en el fondo y la forma, improvisación y coreografía, o sólo en la forma, coreografía (Arranz, 2012).

\subsection{Categoría 2-Enseñanza}

Todas las bailaoras eran o habían sido profesoras de flamenco, si bien, los lugares donde llevaban a cabo su docencia eran diferentes. 


\subsubsection{Subcategoría-2.1. Contenidos}

Las informantes señalaron que los contenidos musicales son relevantes en la enseñanza flamenco: las coreografías que deben memorizar los alumnos pueden estar basadas en la secuencia musical general (atendiendo a la forma y otros parámetros relevantes), o bien, en la estructura rítmica de los pasos, adaptando posteriormente ese fragmento al estilo flamenco escogido. Cuando es la música flamenca la que suscita una serie de movimientos, las informantes toman como referencia las falsetas, los rasgueos del compás, la rueda de tonos, entre otros giros sonoros o la melodía del cante: "Procuro apoyarme en la música", [Informante 1]; "necesito de la música en la mayoría de los casos" [Informante 4].

El compás es un contenido esencial a la hora de enseñar los pasos, siendo el de doce pulsos/tiempos uno de los más complicados de interiorizar, pues consta de 5 acentos situados en los pulsos 3, 6, 8, 10 y 12 ("el compás flamenco no es nada fácil porque sabemos que el bendito compás en doce tiempos", Informante 5). La distribución peculiar de estos acentos, hace que no resulte homogéneo el patrón rítmico y por lo tanto difícil de interiorizar. Además, y con respecto al ritmo, entendido como movimiento musical ordenado en el tiempo (Ness et al., 2006), hay que tener en cuenta que existe una cierta versatilidad y elasticidad del mismo, especialmente en las músicas que son propias de transmisión oral (Berlanga, 2014). Por este motivo, este compás flamenco de 12 pulsos/tiempos se ha transcrito de diferentes formas: tradicionalmente se referenciaba según el palo, por ejemplo, $3 \times 4$ para la soleá y $6 \times 8$ para la seguiriya $\mathrm{y}$, actualmente, en compases alternos de $3 \times 4 / 2 \times 4$ o en compases de $12 \times 4$ colocando acentos según donde se sitúen en cada caso (Pino, 2004). Dentro de estos compases se realiza el ritmo del zapateado. Es por ello, que la enseñanza de la improvisación del ritmo del zapateado era uno de los aspectos más difíciles de hacer llegar a los alumnos, según señalaron algunas de las bailaoras entrevistadas: "intento hacerlo porque pienso que es más divertido (...) igual no [improviso] mucho de sonido por mi capacidad, pero más de mecanismo" (Informante 1). La improvisación, junto con el montaje coreográfico, está muy presente en la práctica escénica del baile flamenco. Los momentos de movimiento libre se producen dentro de la estructura del baile de una manera flexible, pues se presentan en lugares propicios, pero no estrictamente definidos (Pablo y Navarro, 2007).

No obstante, la mayoría de las informantes bailaoras coincidieron en que era el movimiento del cuerpo (brazos y torso) los aspectos más difíciles de enseñar: "la colocación, los brazos", [Informante 1]; "la parte del torso y los brazos a mí me cuesta más enseñarla, porque creo que es una parte física muy personal" [Informante 4]. Sin embargo, dichas complicaciones didácticas no deben ser un obstáculo a la hora de conseguir interpretar un buen baile flamenco (Arranz, 2012). 


\subsubsection{Subcategoría-2.2. Metodología}

La oralidad es el procedimiento que adoptan las entrevistadas para transmitir los contenidos del flamenco. Así, las informantes pusieron de manifiesto que en sus clases, interpretan pasos de baile o melodías de cantes flamencos y los alumnos escuchan y repiten los mismos, memorizando de esta forma los contenidos del flamenco: "Y que ellos escuchen simplemente, (...) se va quedando en el oído (...) que memoricen a base de repetición auditiva" [ Informante 3]. Dicha metodología de enseñanza, a través de la instrucción directa, profesoralumno (Mosston y Ashworth,1993), requiere de la observación y concentración (Arranz 2012).

Uno de los recursos más interesantes que exponen las bailaoras para el aprendizaje del ritmo o del compás flamenco es el conocido como encaje silábico, entendido este como la asignación de una sílaba a cada ataque rítmico, ya sea adjudicando la sílaba a un pulso de un compás o a una figura rítmica (De las Heras-Fernández, 2017). En el caso del compás flamenco de 12 pulsos, los docentes de flamenco nombran con números cada tiempo del compás. El 1 para el pulso 1, el 2 para el pulso 2 y así sucesivamente. Es una manera de contar característica en los bailaores, pues resulta una forma eficaz para la creación de coreografías. Sin embargo, no coincide con la forma de recuento musical en la que esos compases se transcribían y estructuraban en compases de amalgama, por lo que dicho procedimiento ha ocasionado numerosas confusiones (Gamboa y Núñez, 2007). Además, el encaje silábico también se utiliza como recurso para el aprendizaje de secuencias rítmicas del zapateado. Las bailaoras entrevistadas expusieron que procuran inventar frases de texto que coincidan con el acento de las frases rítmicas del zapateado: "Me invento frases. (...) o sea una frase que tenga el mismo acento que tiene el paso" [Informante 2].

Por último, el medio audiovisual es otra herramienta común utilizada por gran parte de las informantes para registrar y conservar aquellos movimientos, sonidos o cantes que luego van a enseñar a los alumnos. Los más utilizados son las grabadoras de vídeo y audio. Actualmente, los móviles están siendo una herramienta indispensable para este cometido: "Grabar con cámara de vídeo y también con sonido", [Informante 5]. Esto viene a reforzar la consideración de algunos especialistas sobre el beneficio de los instrumentos digitales en el proceso de aprendizaje (Amorim, Rego, de Siqueira y Martínez-Saez, 2011).

\section{Conclusiones}

Las conclusiones se llevan a término en función de los objetivos planteados. Así, el análisis narrativo llevado a cabo evidencia que, para la contestación al primero de ellos, debe considerarse el vínculo entre tipo y contexto de enseñanza, que en este caso se advierten como inseparables. De esta forma, en el proceso de aprendizaje del flamenco coexisten los tres tipos 
fundamentales de transmisión y recepción de contenidos y saberes, esto es, formal, no formal e informal (Cremades y Herrera, 2010). El primero de ellos se manifestó en el flamenco de forma tardía y diversa, ya que la revisión de la legislación ha subrayado la heterogeneidad de los criterios académicos y administrativos de cada uno de los diseños curriculares de los planes de estudio llevados a cabo desde los años setenta. Son por tanto, las dos modalidades de aprendizaje restantes las que más presencia han tenido en la historia de la enseñanza de este estilo de música y danza. A su vez, ambas encuentran su correlación en los contextos en los que se lleva a cabo el aprendizaje, a saber, lugares públicos y privados, en ámbito laboral y social, coincidiendo con la categorización realizada por Cruces (2004). Esto muestra un panorama heterogéneo en el que las participantes del estudio pudieron formarse en flamenco, tanto en aspectos dancísticos como en musicales. Con todo, es interesante resaltar como las entrevistadas concuerdan en la especial relevancia ejercida por el magisterio femenino a través de la observación e imitación de coreografías, procedimiento que superaba, para muchas, la influencia proveniente de los saberes aprendidos a través de estudios reglados en ámbitos formales. Así, las palabras de la catedrática de danza Mariemma recuerdan a las de muchas de las informantes: "[...] qué mejor enseñanza que ver bailar a Antonia [Mercé]. Para mí fue más que mil profesores en una academia de baile" (Marinero, 2000, p.174).

Por lo que se refiere al segundo de los objetivos planteados, el estudio constata la utilización de metodologías tradicionales del flamenco, en las que la «tímida» innovación ha venido de la mano de la utilización de recursos como, por ejemplo el citado encaje silábico. Es decir, el cante y el baile han necesitado volver a su fuente primigenia, el arte sonoro, para desarrollar estrategias novedosas. Llegados a este punto, cabría preguntarse:1) sobre la adecuación de los programas curriculares del conservatorio en todas las especialidades de flamenco (cante, toque y baile) y, 2) sobre la posibilidad de implementar diferentes estilos de enseñanza en los contextos formales de aprendizaje. En este sentido, estudios como el de Cuéllar (1999), en el que se introducen metodologías de Educación Física (Mosston, 1981) en el baile flamenco escolar, podrían ser replicables en centros superiores como conservatorios, incluyendo la reforma de dichos estilos de enseñanza (Mosston y Ashworth, 1993). Si bien, sería conveniente que el profesorado de flamenco estuviera dispuesto a conocer otras formas de enseñanza, e incluso, conocer los distintos estilos de aprendizaje del alumnado (Ríos, 2019) y que los programas profundizaran en el conocimiento didáctico de su disciplina para mejorar el proceso, motivar a los alumnos y que estos disfrutarán, aún más, del conocimiento del flamenco.

A raíz de todo lo expuesto, la presente investigación llega a una serie de consideraciones finales. A pesar de la inclusión del baile y del cante dentro de los estudios oficiales reglados del conservatorio, el flamenco no ha sufrido una modificación esencial en cuanto a su proceso de enseñanza-aprendizaje. Las informantes vuelven a referenciar, casi de manera literal, todo lo 
que las fuentes documentales históricas han señalado, convergiendo en dos puntos principales: por un lado, el flamenco es un arte de transmisión oral y, por otro lado, las compañías de danza, los tablaos y los espectáculos siguen siendo el contexto principal para llevar a cabo su aprendizaje. Esto quiere decir que, (a) a pesar de los esfuerzos legislativos por ordenar este conjunto de enseñanzas y (b) aun cuando se percibe una vertiente divulgativa, en la cual se resalta y se pone énfasis a la cultura flamenca desde un punto de vista más amplio que el puramente teórico o investigador (Cenizo, 2010) con el fin de llegar a más capas de la sociedad, el flamenco, como forma de aprendizaje, está principalmente fuera de la academia. Este hecho puede corroborarse, incluso, si se atiende a su presencia dentro del currículum del resto de niveles educativos: de este modo, solo la Comunidad Autónoma de Andalucía lo ha incluido dentro de su plan general de estudios. En este sentido, la Ley Orgánica 2/2007 de 19 de marzo establece que "[c]orresponde [...] a la Comunidad Autónoma la competencia exclusiva en materia de conocimiento, conservación, investigación, formación, promoción y difusión del flamenco como elemento singular del patrimonio cultural andaluz" (p.2).

Esta marginalidad de la enseñanza del flamenco fomenta la situación de educación primigenia, a la manera socrática, que las entrevistas han vuelto a subrayar: lo aprendido se recibe a través del oído y se procesa intelectualmente gracias al buen hacer docente, que debe saber transmitir aquel conocimiento que, en su gran parte, no está escrito. Es por esto, además, que el término de "flamenco puro" que resaltan las fuentes bibliográficas tiene su correlación con el "aprendizaje puro", de aquel que lo adquirió a través del ejemplo continuo que solo puede darse en las compañías de danza. El papel de la mujer en todo este proceso es el mismo que en el siglo XVIII: sigue siendo la figura que tiene que hacer conceptual un aprendizaje que ha adquirido de modo procedimental.

En conclusión, la transmisión del flamenco, en cualquiera de sus contextos de aprendizaje, sigue siendo un juego de contrarios, en la que la maestra ha tenido que tomar conciencia y saber transmitir la bipolaridad inherente al arte que pretende ser enseñado: el arte frente a la técnica, la improvisación en oposición a los recursos técnicos y la espontaneidad contra el academicismo.

\section{Referencias}

Amorim, J. D. A., Rego, I., de Siqueira, J. M. y Martínez-Saez, A. (2011). Defining the design parameters of a teacher training course on the incorporation of ICT into teaching practices. Procedia: Social and Behavioral Sciences, 15, 653-657. doi: 10.1016/j.sbspro.2011.03.158

Arranz A. (2012). El baile flamenco. Madrid: Librerías Deportivas Esteban Sanz Martínez. 
Atencia, L. (2015). Desarrollo histórico y evolutivo del baile flamenco: De los bailes de candil a las nuevas tendencias en el baile flamenco. La Madrugá: Revista de Investigación sobre Flamenco, (12), 139-153.

Berlanga, M. A. (2014). La originalidad musical del flamenco: el compás. Sinfonía Virtual, 26, $1-20$.

Birks, M. y Mills, J. (2011). Grounded theory: A practical guide. London: Sage.

Casas-Mas, A., Pozo, J. I. y Montero, I. (2014). The influence of music learning cultures on the construction of teaching-learning conceptions. British Journal of Music Education, 31 (3), 319342. doi: $10.1017 / \mathrm{S} 0265051714000096$

Cenizo, J. (2010). Una experiencia en enseñanza secundaria estudio de las coplas flamenca desde un punto de vista interdisciplinar. Revista de Investigación sobre flamenco, Revista de Investigación sobre Flamenco: La Madrugá, 3, 1-8.

Colás, M.P. y Rebollo, M.A. (1993). Evaluación de programas. Una guía práctica. Sevilla: Kronos.

Cremades, R. y Herrera, L. (2010). Estudio comparativo de la educación formal e informal en el conocimiento musical de los estudiantes de enseñanza profesional de música. Publicaciones, 40, 73-87.

Cruces, C. (2004). El flamenco en la Universidad. Presentación de una experiencia curricular y docente. En M. López (Coord.), Introducción al flamenco en el currículum escolar (pp. 107171). Madrid: Akal.

Cuéllar, M. J. (1999). Estudio de la Adaptación de los Estilos de Enseñanza a sesiones de Danza Flamenca escolar. Un nuevo planteamiento didáctico (Tesis Doctoral). Granada: Universidad de Granada. Recuperado de http://digibug.ugr.es/handle/10481/14546

De las Heras-Fernández, R. (2017). Propuesta de adaptación de métodos didácticos para el aprendizaje de conceptos rítmicos básicos aplicados a la enseñanza en el zapateado flamenco. El encaje silábico y la improvisación. Revista del Centro de Investigación Flamenco Telethusa, 10(12). p. 11-18. doi:10.23754/telethusa.101202.2017

Del Campo, A. y Cáceres, R. (2013). Historia cultural del flamenco. El barbero y la guitarra. Madrid: Almazura. 
Dorantes-Nova, J. A., Hernández-Mosquera, J. S. y Tobón-Tobón, S. (2016). Juicio de expertos para la validación de un instrumento de medición del síndrome de burnout en la docencia. $R a$ Ximhai, 12 (6), 327-346.

Fernández, I. F., Sagardia, A. E., Loroño, M. A., de Gauna Bahillo, P. R., y Ramos, A. E. (2012). Creatividad e innovación: claves para intervenir en contextos de aprendizaje. REICE: Revista Electrónica Iberoamericana sobre Calidad, Eficacia y Cambio en Educación, 10(2), 23-40.

Gamboa, J. y Núñez, F. (2007). Diccionario de flamenco de la A a la Z. Diccionario de términos del flamenco. Madrid: Espasa Calpe.

García-Huidobro, R. (2016). Diálogos, desplazamientos y experiencias del saber pedagógico. Una investigación biográfica narrativa con mujeres artistas-docentes. Tesis doctoral. Universidad de Barcelona. Recuperado de: http://hdl.handle.net/2445/102787

Gibbs, G. (2012). El análisis de datos cualitativos en Investigación Cualitativa. Madrid: Ediciones Morata.

Jefatura del Estado. (1990). Ley Orgánica 1/1990, de 3 de octubre, de Ordenación General del Sistema Educativo. BOE (04/10/1990), núm. 238, referencia 24172, pp.28927-28942.

Jefatura del Estado. (2015). Ley 10/2015, de 26 de mayo, para la salvaguardia del Patrimonio cultural. BOE (27/05/2015), núm. 126, referencia 5794, pp.45285-45301.

Jefatura del Estado. (2007). Ley Orgánica 2/2007, de 19 de marzo, de reforma del Estatuto de Autonomía para Andalucía. BOE (20/03/2007), BOJA (20/03/2007), núm. 68, referencia 5825, pp.11871-11909.

Kvale, S. (2011). Las entrevistas en investigación cualitativa. Madrid: Ediciones Morata.

Marinero, C. (2000). «Mariemma [Guillermina Martínez Cabrejas]”. En M. Casares. (Coord. y Ed.), Diccionario de la Música Española e Hispanoamericana (pp. 174-175). Madrid: Sociedad General de Autores y Editores.

Martínez, T. (1969). Teoría y práctica del baile flamenco. Madrid: Aguilar.

Ministerio de Cultura y Deporte. (2018). Resolución de 13 de noviembre de 2018, de la Dirección General de Bellas Artes, por la que se incoa expediente de declaración de la Danza Española como manifestación representativa del Patrimonio Cultural Inmaterial. BOE (12/12/2018), núm. 299, referencia16999, pp.121894-121908. 
Ministerio de Educación. (2010). Real Decreto 632/2010, de 14 de mayo, por el que se regula el contenido básico de las enseñanzas artísticas superiores de Grado en Danza establecidas en la Ley Orgánica 2/2006, de 3 de mayo, de Educación. BOE (5/06/2010), núm.137, 8956, pp.48501-48516.

Ministerio de Educación y Ciencia. (2007). Real Decreto 85/2007, de 26 de enero, por el que se fijan los aspectos básicos del currículo de las enseñanzas profesionales de danza reguladas por la Ley Orgánica 2/2006, de 3 de mayo, de Educación. BOE (13/02/2007), núm. 38, 2956, pp.6249-6262

Ministerio de Educación y Cultura. (1997). Real Decreto 1254/1997, de 24 de julio, por el que se establecen los aspectos básicos del currículo del grado medio de las enseñanzas de Danza. BOE (04/09/1997), núm. 212, referencia 19358, pp.26307-26318.

Ministerio de Educación, Cultura y Deporte. (2004). Real Decreto 169/2004, de 30 de enero, por el que se establecen los requisitos para obtener la equivalencia entre los estudios completos de danza anteriores a la Ley Orgánica 1/1990, de 3 de octubre, de Ordenación General del Sistema Educativo, y los estudios superiores de danza regulados en ella, y se establecen los complementos de formación para la obtención del título superior de Danza. BOE (13/02/2004), núm. 38, referencia 2652, pp.6658-6660.

Mosston, M. y Ashworth, S. (1993). La enseñanza de la Educación Física. La reforma de los estilos de enseñanza. Barcelona: Editorial Hispano Europea.

Mosston, M. (1981). Teaching Physical Education (second ed.). Columbus, OH: Merrill.

Navarro, J. L. y Palo, E. (2005). El baile flamenco. Aproximación histórica. Córdoba: Almuzara.

Ness, A. J., Gustafson, B., Harden, B. J. et al. (2006). Diccionario Harvard de Música. Madrid: Alianza Editorial.

Pablo, E. y Navarro, J. L. (2007). Figuras pasos y mudanzas. Claves para conocer el baile flamenco. Córdoba: Almuzara.

Pantoja Antúnez, J. L. (1963). Evocación de las grandes figuras el flamenco. Jérez de la Frontera: Asta Regia.

Pino, D. (2004). El compás flamenco. En M. López (Coord.), Introducción al flamenco en el currículum escolar (pp. 107-171). Madrid: Akal.

Pohren, D. E. (1970). El arte del flamenco. Sevilla: Sociedad de Estudios Españoles.

@ROSA DE LAS HERAS FERNÁNDEZ Y DESIRÉE GARCIAA GIL. THE CONTENT OF THIS ARTICLE IS THE SOLE RESPONSIBILITY OF THE AUTHORS. THE REVISTA ELECTRÓNICA DE LEEME AND UNIVERSITAT DE VALĖNCIA ARE NOT LIABLE FOR ANY LEGAL ACTIONS THAT MAY ARISE INVOLVING THE ARTICLE'S CONTENT. REVISTA ELECTRÓNICA DE LEEME - UISTA ELECTRÓNICA EUROPEA DE MÚSICA EN LA EDUCACIÓN-HTTP://OJS.UV.ES/INDEX/PHP/LEEME/INDEX. ISSN: 1575-9563. EDITORES: UNIVERSIDAD DE VALENCIA Y JESÚS TEJADA GIMÉNEZ. VISIBILIDAD DE ESTA REVISTA: SCOPUS, EMERGING SOURCES CITATION INDEX (CLARIVATE), EBSCO, CINDOC (CSIC), CITEFACTOR, COPAC, DIALNET, DICE (CSIC), DOAJ, E-REVISTAS (CSIC), EBSCO PREMIER, ERIH+, GALE CENGAGE LEARNING, IN-RECS, IRESIE, LATINDEX, MIAR, OCLC WORLDCAT, RESH, REDIB, RILM CORE JOURNALS, SUDOC, ULRICHS, ESTA REVISTA ESTÁ PUBLICADA CON EL APOYO INSTITUCIONAL DE REDIRIS-CONSEJO SUPERIOR DE INVESTIGACIONES CIENTIFICAS Y ES DE ACCESO LIBRE. CREATIVE COMMONS LICENSE 4.0 BY 
Puig Claramunt, A. (1977). El arte del baile flamenco. Barcelona: Polígrafa.

Ríos, R. P. (2019). Las Teorías de Enseñanza y los Estilos de Aprendizaje y los Modelos Teóricos para ajustarlos/Teaching Theories, Learning Styles and Theoretical Models for their Adjustment. Revista Internacional de Aprendizaje en la Educación Superior, 6 (1), 21-34.

Ríos, M. (2002). Andalucía. En E. Casares Rodicio (Ed.), Diccionario de la música española e hispanoamericana. Vol. 1 (pp.432-443). Madrid: Editorial Cinterco.

Ríos-Ruíz, M. (2002). El gran libro del Flamenco. Volumen II. Intérpretes. Barcelona: Calambur.

Ruiz-Olabuénaga, J. L. (2007). Metodología de investigación cualitativa. Bilbao: Universidad de Deusto.

Sandín, M. P. (2000). Criterios de validez en la investigación cualitativa: De la objetividad a la solidaridad. Revista de Investigación Educativa, 1 (18), 223-242.

Steingress, G. (2004) Sobre flamenco y flamencología. Escritos escogidos 1988-1998. Sevilla: Signatura Ediciones de Andalucía.

Syrmpas, I. y Digelidis, N. (2014). Physical education student teachers' experiences with and perceptions of teaching styles. Journal of Physical Education and Sport, 14 (1), 52-59. doi: 10.7752/jpes.2014.01009 